\title{
Non-destructive analysis of mummification balms in Ancient Egypt, based on EPR of vanadyl and organic radical markers of bitumen.
}

\author{
Charles E. Dutoit, ${ }^{* \dagger}$ Laurent Binet, ${ }^{\dagger}$ Hitomi Fujii, ${ }^{\ddagger}$ Agnes Lattuati-Derieux, ${ }^{\ddagger}$ Didier Gourier $*^{\dagger}$ \\ †Chimie-ParisTech, PSL University, CNRS, Institut de Recherche de Chimie-Paris (IRCP), F-75005 Paris, France \\ \# Centre de Recherche et de Restauration des Musées de France (C2RMF), Palais du Louvre, F-75001 Paris, France
}

\begin{abstract}
The black matter employed in funeral context by ancient Egyptian is a complex mixture of plant-based compounds with variable amounts of bitumen. Asphaltene, the most resistant component of bitumen, contain Vanadyl porphyrins and carbonaceous radicals which can be used as paramagnetic probes to investigate embalming materials without sample preparation. Electron Paramagnetic Resonance (EPR) at X-band, combining in-phase and out-of-phase detection schemes, provides new information in a non-destructive way about the presence, the origin, and the evolution of bitumen in these complex materials. It is found that the relative EPR intensity of radicals and vanadyl porphyrins is sensitive to the origin of the bitumen. The presence of non-porphyrinic vanadyl complexes in historical samples is likely due to the complexation of $\mathrm{VO}^{2+}$ ions by carboxylic functions at the interface between bitumen and other biological components of the embalming matter. The absence of such oxygenated vanadyl complex in natural bitumen and in one case of historical human mummy acquired by a museum in the $19^{\text {th }}$ century reveals a possible, nondocumented, ancient restoration of this mummy by pure bitumen. The linear correlation between in-phase and out-of phase EPR intensities of radicals and vanadyl porphyrins in balms and in natural bitumen, reveals a nanostructuration of radicals and vanadyl porphyrin complexes, which was not affected by the preparation of the balm. This points to the remarkable chemical stability of paramagnetic probes in historical bitumen in ancient Egypt.
\end{abstract}

Embalming matter and other "black matter" used in ancient Egypt are complex mixtures of natural compounds such as sugar gum, beeswax, fats, coniferous resins, bitumen and so on. ${ }^{1-3}$ Each of these substances are characterized by specific molecular biomarkers identified by various methods of analytical organic chemistry, among which gas chromatography-mass spectrometry (GC/MS), pyrolysis-gas chromatography-mass spectrometry (PyGC/MS) are the most commonly used. Since the 19th century, and in spite of many controversies, egyptologists have believed that the dark color of mummies is due to the presence of bitumen. ${ }^{4-8}$ Based on specific molecular biomarkers, mainly hopanes and steranes, and on radiocarbon analysis (bitumen has lost its ${ }^{14} \mathrm{C}$ ), it was concluded that bitumen was increasingly used for mummification receipts from the New Kingdom (ca 1550-1070 BC) to the Ptolemaïc/Roman period (332 BC- IV ${ }^{\text {th }}$ century AC). ${ }^{3}$ Although the ensemble of destructive organic analytical and radiocarbon methods used so far are powerful to study separately the many pieces of the puzzle, there doesn't seem to be a method for analyzing the whole puzzle, i.e. in a non-destructive manner. This is understandable given the extreme chemical complexity of these embalming materials, which necessitates preparation and separation steps prior to a detailed molecular or isotopic analysis. A complementary, but different method could be to analyze these materials "from the inside" using internal probes already present in very small quantities, but which would provide information on their environment. It is well known that oil, kerogens and bitumen contain variable amounts of vanadyl porphyrins (up to $1000 \mathrm{ppm}$ ), which originate from photosynthetic life in primitive marine environment (which provide porphyrinic molecules). Vanadyl porphyrins are formed by substitution of $\mathrm{Mg}^{2+}$ ion of chlorophyll by $\mathrm{VO}^{2+}$ ions during diagenesis. ${ }^{9}$ Carbonaceous radicals are also formed during the geological evolution of the fossil biological mater. ${ }^{10-12}$ Vanadyl porphyrin complexes and carbonaceous radicals are mainly located in the asphaltene component of the bitumen, a tridimensional polymerized architecture which is resistant to biodegradation and oxidation. ${ }^{13}$ In this work, we explore the possibility of analyzing by Electron Paramagnetic Resonance (EPR) spectroscopy the vanadyl complexes and organic radicals in historical samples of black matter taken from historical human and animal Egyptian mummies. The main objective is to use these stable paramagnetic probes to obtain information on the presence, origin, processing, and evolution of bitumen in embalming matter. These data are faced to molecular characterization obtain from classical GC/MS approach.

\section{EXPERIMENTAL SECTION}


Samples. The samples of black matter studied in this work come from various human and animal mummies of the ancient Egypt stored in museum collections. They were compared with three references samples: a natural asphalt from Dead Sea ( $\boldsymbol{R} \boldsymbol{e f} \mathbf{1})$, a commercial bitumen of Judea (Ref 2), and a bitumen from the tar seep of the Puy de la Poix, Clermont-Ferrand, France $(\boldsymbol{T S})$. Three samples of black matter were taken from an anthropomorphic coffin (Hum 1) and two human mummies (Hum 2 and Hum 3). Four samples were taken from animal mummies, three rams $(A n$ 1, $A n$ 2, $A n$ 3) and one crocodile (An 4). All these samples date from the Late Period to the Ptolemaic period (744 BC to $30 \mathrm{BC}$ ). All samples (10-20 mg) were inserted into quartz suprasil EPR tubes. The characteristics of the samples are summarized in Table 1, and described in more details in Supporting Information Table S1.

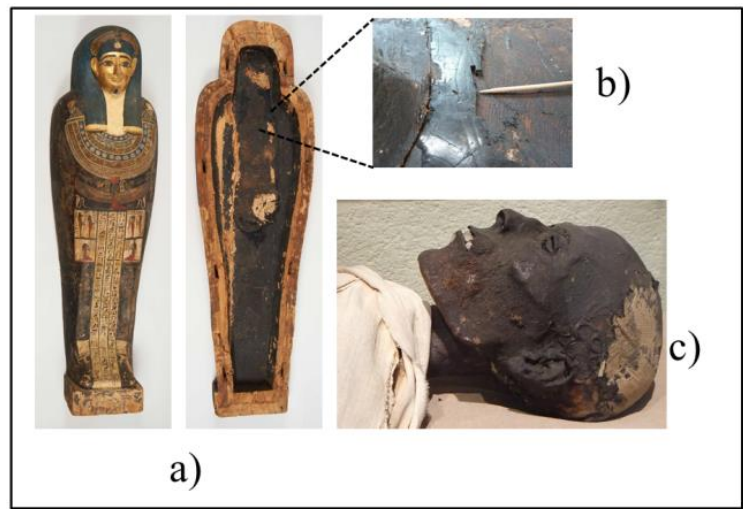

Figure 1. Two examples of samples of black matter studied in this work; a) Coffin of Irethorerou (Ptolemaïc Period), Musée d'Art et d'Histoire, Narbonne, France, and b) Black matter at the bottom of the coffin from which the sample Hum 1 was taken (C) C2RMF/A.Chauvet; c) Head of the mummy of a bearded man (Late Period), Chateau-musée, Boulogne-sur-Mer, France. Sample Hum 3 was taken from the mummy's neck. (C) P. Dal-Pra.

Electron paramagnetic resonance (EPR). Continuous wave Electron paramagnetic resonance (cw-EPR) measurements were performed at room temperature with a conventional Bruker X-band Bruker Elexsys E500 spectrometer operating at about $9.6 \mathrm{GHz}$, equipped with a high sensitivity $4122 \mathrm{SHQE} / 0111$ microwave cavity. The microwave power into the cavity was set at $2 \mathrm{~mW}$ in order to avoid saturation of the EPR spectrum. The modulation frequency and modulation depth of the static magnetic field were chosen at $100 \mathrm{kHz}$ and $0.5 \mathrm{mT}$, respectively. Simulation of cw-EPR spectra were done with the EasySpin package for Matlab. ${ }^{14}$ The g-factors and the hyperfine interaction were fitted manually to achieve good similitude between experimental and simulated spectra. Complementary separative and molecular analyses were performed on Huml and Hum 3 samples using GC/MS (see Supporting Information). These analyses aimed to identify a large range of natural substances (e.g. fats, waxes, terpenoid resins and bitumen) that could be possibly present in the selected samples.

\section{RESULTS AND DISCUSSION}

Continuous wave EPR spectroscopy. The EPR spectrum at X-band of the Dead Sea asphalt sample ( $\boldsymbol{R e f} \mathbf{1})$ exhibits the two paramagnetic species classically found in bitumen and oil (Fig.3a): ${ }^{10,15-17}$ (i) a single and intense line in the central part of the spectrum $(\sim 335 \mathrm{mT}, g=1.9994)$, corresponding to free organic radicals $(S=1 / 2)$, hereafter referred to as $\mathrm{C}^{0}$, and (ii) a multi-line spectrum of vanadyl porphyrins in asphaltene, hereafter referred to as VO-P. The shape of this spectrum is dominated by the central $\mathrm{VO}^{2+}$ ion of VO-P (Fig.2), which bears an unpaired electron spin $S=1 / 2$ in the $\mathrm{d}_{\mathrm{xy}}$ orbital of $\mathrm{V}^{4+}\left(3 \mathrm{~d}^{1}\right.$ configuration) in the porphyrin plane, with lobes pointing between $\mathrm{N}$ atoms of pyrolic groups. The hyperfine interaction of the electron spin $S$ with the nuclear spin $I=7 / 2$ of the central ${ }^{51} \mathrm{~V}$ nucleus (100\% abundance) gives two sets of $2 I+1$ $=8$ hyperfine lines. The most extended and weaker set of lines, characterized by parameters $g_{/ /}$and $A_{/ /}$, corresponds to VO-P complexes with V-O bond oriented along the external field $\mathbf{B}_{0}$. The most intense central set of 8 lines, with parameters $\mathrm{g}_{\perp}$ and $\mathrm{A}_{\perp}$, corresponds to complexes with $\mathbf{B}_{0}$ in the porphyrin plane (perpendicular to the VO bond). The bitumen of Judea ( Ref 2 ) gives the same EPR spectrum (see Fig. S1a in Supporting Information).

\section{Table 1. Samples of black matter studied by EPR}

\begin{tabular}{cl} 
Label & \multicolumn{1}{c}{ Object } \\
Ref 1 & Natural asphalt with $\mathrm{VO}^{2+}$, from the Dead Sea \\
Ref 2 & Commercial bitumen of Judea \\
TS & Natural bitumen with no $\mathrm{VO}^{2+}$, France \\
Hum 1 & $\begin{array}{l}\text { Anthropomorphic coffin, upper Egypt, Ptol- } \\
\text { emaïc period (332 BC-30 BC). Black matter } \\
\text { in the bottom of the coffin }\end{array}$
\end{tabular}

Hum 2 Human mummy, Egypt, late Period (end of the $\mathrm{IV}^{\text {th }}$ century $\left.\mathrm{BC}\right)$; dark matter covering the mummy

Hum 3 Human mummy, Egypt, Late Period (XXI ${ }^{\text {th }}$ $\mathrm{XXV}^{\text {th }}$ dynasty ?). Black matter taken from the neck of the mummy.

An 1 Ram mummy, Upper Egypt, Late Period; 672 BC-322 BC; black matter covering the mummy.

An 2 Ram mummy, Upper Egypt, Late Period (664 BC-332 BC); black matter covering the mummy

An 3 Ram mummy (the same as An 2); tissue with brown matter covering the mummy.

An 4 Crocodile mummy, Upper Egypt, Ptolemaïc period; black matter covering the skull. 


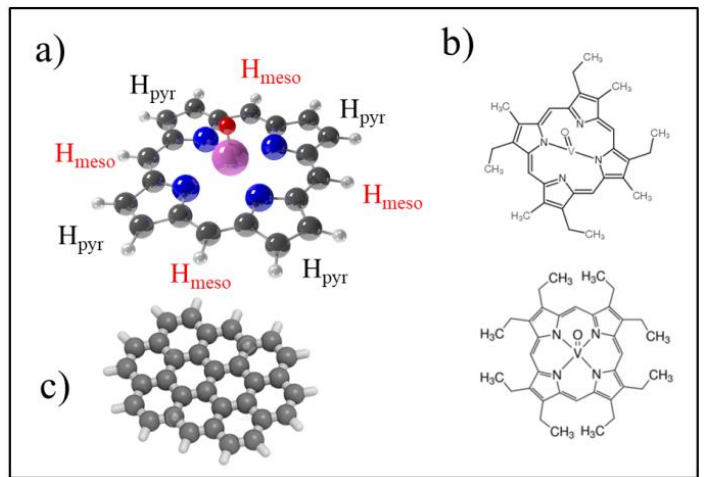

Figure 2. a) Chemical structure of a VO porphyrin model; b) top: VO-etioporphyrin (VOEtio) and bottom: VO-octaethyl porphyrin (VOOEP), among the most common geoporphyrins; c) schematic representation of a polyaromatic radical.

EPR spectra of historical samples of black matter exhibit the same general pattern, as exemplified in Fig.3b for the Ptolemaïc coffin (Hum 1). The other spectra are given in Supporting Information. Except for Hum 3 sample (the bearded man from the Boulogne museum, Figs. 1c and $\mathrm{S} 1 \mathrm{~b})$, all the historical samples exhibit distinct EPR features (Figs. 3, S1 and S2): (i) a VO-P spectrum less intense than in reference samples for the same mass of matter (ii) additional hyperfine lines, marked by green circles in Fig.3b, and (iii) a very broad line covering all the spectrum, due to traces of ferromagnetic mineral particles (iron oxides). The manifestation of the latter is a distortion of the baseline of the $\mathrm{VO}^{2+}$ spectrum, and it will not be considered further in this work. The additional hyperfine lines in historical samples are clearly due to a second $\mathrm{VO}^{2+}$ species (hereafter referred to as VO-nP), as shown by the simulation of EPR spectra (Fig.3c). The shapes of the hyperfine patterns of VO-P and VO-nP are very similar, except for the resonance field of each hyperfine line, which indicate that the EPR parameters of these two vanadyl complexes are different.

The simulation parameters for each sample are given in Supporting Information Table S2. The mean values of the EPR parameters are given in Table 2, the error bars representing the dispersion of simulated values. It is well known that EPR parameters $g$ and $A$ of $\mathrm{V}^{4+}$ are sensitive to the symmetry and the nature of its sphere of coordination, ${ }^{18}$ which can be visualized in a diagram representing $g_{/ /}$versus $A_{/ /}$for the 9 samples (Fig.4a). The background of this diagram is built from multiple experimental data collected in the literature for $\mathrm{V}^{4+}$ and $\mathrm{VO}^{2+}$ in various mineral matrices and vanadyl complexes (Ref. 19 and references therein). The colored triangle in the lower left part of Fig.4a represents the location of data for $\mathrm{V}^{4+}$ in oxide minerals, and the ellipses (solid lines) in the upper right part represent the location of data for vanadyl complexes with different types of first neighbor atoms (4S, $4 \mathrm{~N}, 2 \mathrm{~N} 2 \mathrm{O}$ and $4 \mathrm{O}$ ). It can be seen that VO-P spectra of all samples (Ref, Hum and $\boldsymbol{A n}$ ) have four N ligands, as expected for vanadyl porphyrins. VO-nP spectra of histor- ical samples have clearly four oxygenated ligands, which indicates that the VO-nP species found in historical samples are non-porphyrinic vanadyl complexes.
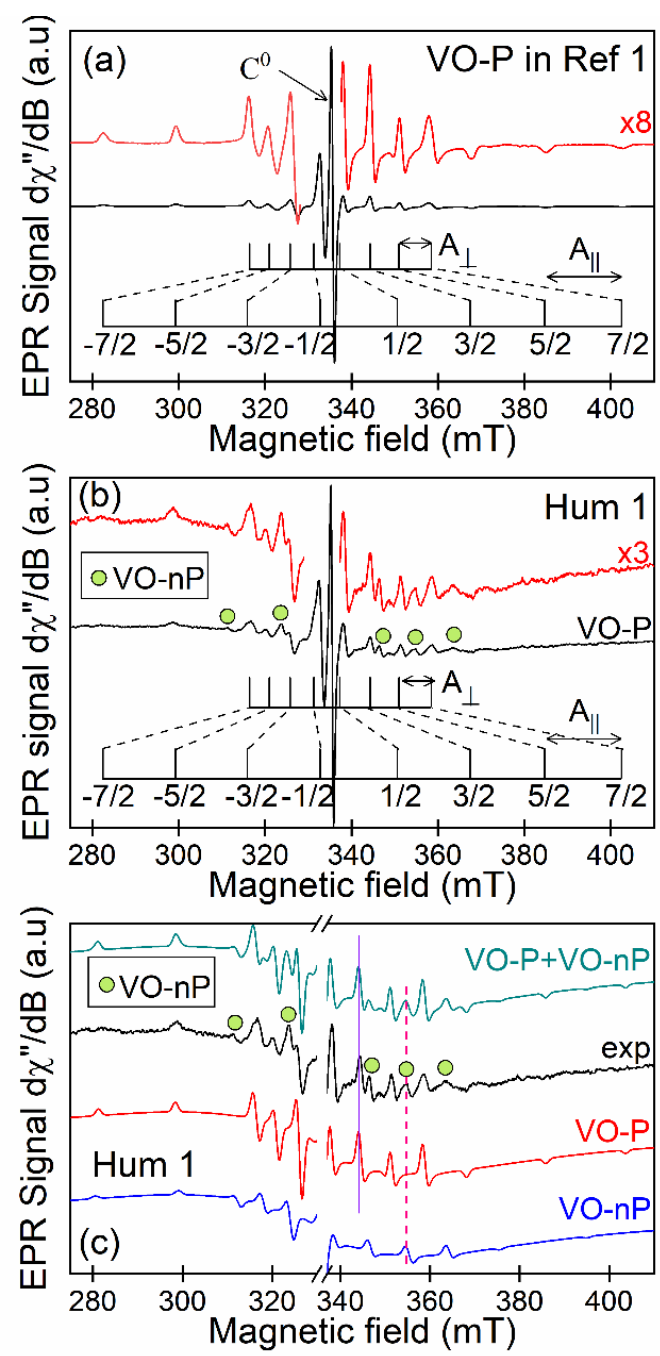

Figure 3. EPR spectra at X-band and room temperature of two samples of black matter: a) asphalt from the Dead Sea Ref 1; b) black matter in the Ptolemaïc coffin Hum 1; c) simulation of the EPR spectrum of Hum 1; some EPR lines of $\mathrm{VO}-\mathrm{nP}$ are represented by green circles.

Table 2. Mean values of EPR parameters of vanadyl complexes. Hyperfine interaction $A$ is given in $\left(10^{-4} \mathrm{~cm}^{-1}\right)$

$\begin{array}{lcccc}\text { Complex } & \mathrm{g}_{/ /} & \mathrm{g}_{\perp} & \mathrm{A}_{/ /} & \mathrm{A}_{\perp} \\ \text { VO-P } & 1.957 \pm 0.002 & 1.978 \pm 0.002 & 158 \pm 3 & 55 \pm 2 \\ \text { VO-nP } & 1.925 \pm 0.003 & 1.978 \pm 0.003 & 176 \pm 3 & 70 \pm 3\end{array}$

As the black matter used in ancient Egypt was generally a complex mixture of plant-based resins and bitumen (mainly from Dead sea), ${ }^{1-3,20-23}$ we may compare the amount of VO-P for each sample and for the same sample mass, relative to the Dead sea asphalt ( $\boldsymbol{R} \boldsymbol{e f} \boldsymbol{1})$ taken as the reference $(100 \%$ of VO-P). The results are given in 
Fig.4b. Samples from animal mummies (An 1-4) are characterized by almost the same proportion of VO-P (10 to $20 \%$ ), while samples of black matter from human mummies or coffin are poorly enriched ( $5 \%$ for $\mathbf{H u m ~} \mathbf{I}$ and Hum 2) or very enriched (40\% for Hum 3) in VO-P. The amount of VO-P in sample Hum 3 is very similar to that in the commercial bitumen of Judea Ref 2 . In principle, these relative amounts of VO-P could be an indication of the proportion of bitumen in the black matter. However this would be true only if the bitumen of all samples came from the same region, as the vanadyl content of bitumen is dependent on the geological formation. Even in the case of the floating blocks of Dead Sea asphalt exploited in the antiquity, it has been observed that blocks taken from the northern part of the lake are rich in VO-P, while those taken from the southern part are poor. ${ }^{10}$ As the chemical analysis of Hum 3 indicates that it is pure bitumen (see Supporting Information), we may conclude that this bitumen contains less VO-P than the Dead Sea asphalt of $\boldsymbol{R} \boldsymbol{e f} \boldsymbol{1}$.
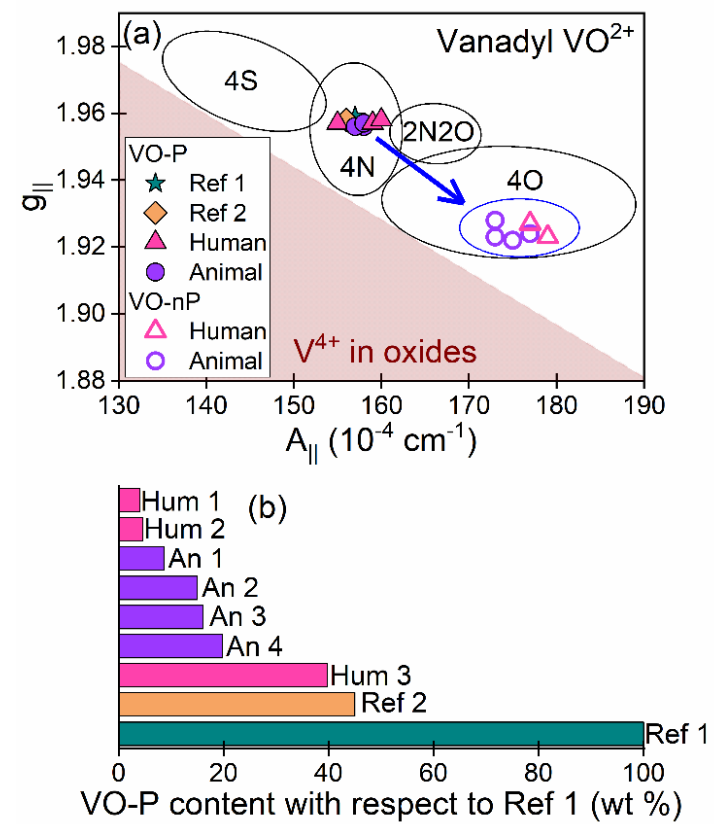

Figure 4. a) Diagram representing g// versus $\mathrm{A} / /$ for $\mathrm{V}^{4+}$; the pink triangle in the lower part represents the location of data for $\mathrm{V}^{4+}$ ions in oxides; The ellipses represent the cases of $\mathrm{VO}^{2+}$ ions with different types of ligands; b) Histogram of VO-P content, with respect to the asphalt from the Dead Sea (Ref 1).

For this reason, it is necessary to use another marker in addition to the VO-P content of the black matter. The free carbonaceous radicals $\mathrm{C}^{0}$, responsible for the intense central line of EPR spectra (Fig.3), are ubiquitous in all mature kerogens, even those older than 3 billion years or in carbonaceous meteorites. ${ }^{24-27}$ Consequently, the $\mathrm{C}^{0}$ line is present in all bitumen, either of marine origin (with VO$\mathrm{P}$ ) or of land-plant origin (without VO-P). The latter case is illustrated with the bitumen from the tar seep of the Puy de la Poix, Clermont-Ferrand, France (sample $\boldsymbol{T S}$ ), which exhibits no VO-P signal, but an intense $\mathrm{C}^{0}$ line and additional hyperfine lines due to $\mathrm{Mn}^{2+}$ ions (Fig.S3). Thus, useful information about the origin and evolution of bitumen in historical samples can be obtained from correlations between the three internal probes VO-P, VO-nP and $\mathrm{C}^{0}$.
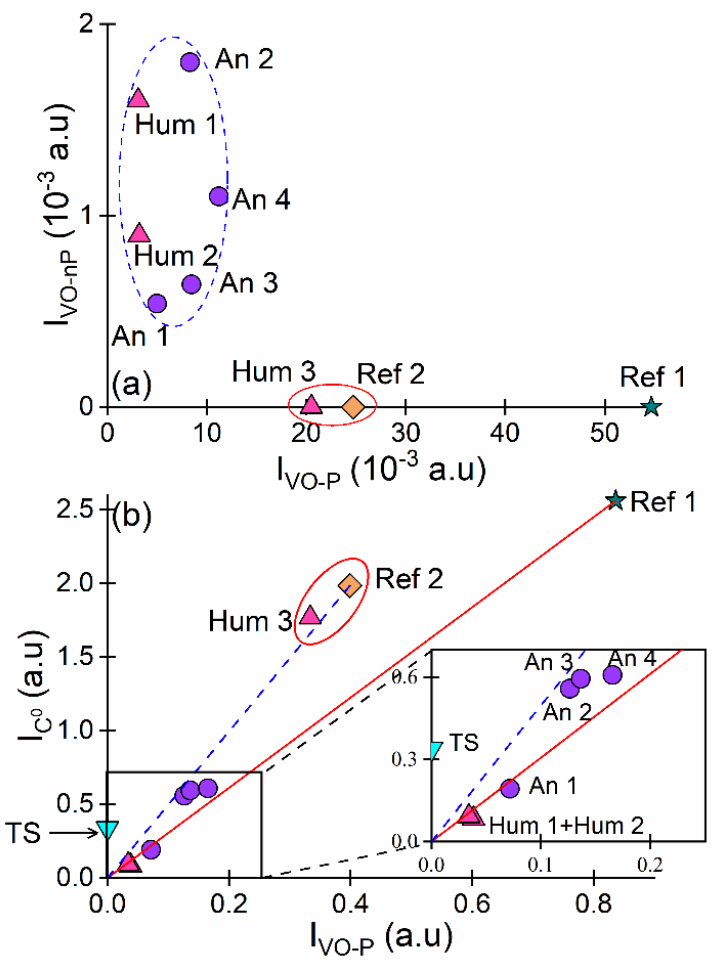

Figure 5. Diagrams representing EPR intensities of VO-P, VO-nP and $\mathrm{C}^{0}$ for the same mass of matter; a) VO-nP versus VO-P; b) $\mathrm{C}^{0}$ versus VO-P. The inset represents a zoom of the lower part of the diagram.

Figure 5a represents the intensities $I_{\text {VO-nP }}$ versus $I_{\text {VO-P }}$ of the non-porphyrinic and porphyrinic vanadyl complexes, respectively. The intensities, measured from the amplitude of the $+5 / 2 \perp$ hyperfine line of the $\mathrm{VO}^{2+}$ spectrum (see Fig. $3 \mathrm{~b}$ for the identification of this line), are given for the same mass of matter. It can be seen in this diagram that all historical samples, except Hum 3, contain VO-nP complexes in variable amounts, and their data are clustered in the same region of the diagram. The positions of Hum 3 and the commercial bitumen $\boldsymbol{R}$ ef 2 are very close in the diagram, which suggests that Hum 3 is anomalous compared to other historical samples.

This impression is reinforced in an independent diagram representing, for the same mass of matter, the amplitude of the $\mathrm{C}^{0}$ line versus the amplitude of the $-1 / 2 \perp$ transition of vanadyl porphyrins VO-P (Fig.5b). Considering again the Dead Sea asphalt ( Ref 1) and the commercial bitumen (Ref 2) as reference samples (pure bitumen), all archeological samples are characterized by a ratio $I_{C^{0}} / I_{V O-P} \approx 3$ 5. The red line and the interrupted blue line in Fig.5b cor- 
respond to $I_{C^{0}} / I_{V O-P} \approx 3$ and 5 , respectively. In order to obtain more information about the origin of bitumen, we must consider that the black matter in ancient Egypt is a mixture of bitumen with other types of biological matter (plant-based resin, beeswax, animal fat ...). Vanadyl porphyrins VO-P are exclusively localized in bitumen, while in principle radicals $\mathrm{C}^{0}$ may be localized both in bitumen and in the other component, so that the intensities $I_{V O-P}$ and $I_{C^{0}}$ can be written:

$$
\begin{aligned}
I_{V O-P} & =k_{1}[\text { Bitumen }] \\
I_{C^{0}} & =k_{2}[\text { Bitumen }]+k_{3}[\text { Other }] \\
1 & =[\text { Bitumen }]+[\text { Other }]
\end{aligned}
$$

where [bitumen] and [other] represent the relative mass content of bitumen and biological material in the black matter. Coefficients $k_{\mathrm{i}}(\mathrm{i}=1,2,3)$ depend on several factors, such as the geological context and setting of the bitumen, the composition of the other component of the black matter, or the chemical and physical treatments used for the preparation of the embalming mixture. In particular, although most bitumen of marine origin contain significant amounts of VO-P complexes, bitumen from terrestrial plants origin do not contain these complexes or only a very small amount. ${ }^{10}$ So $k_{1}$ can have a wide range of values, including zero (no VO-P). This is the case for reference sample $\boldsymbol{T S}$ (Fig.S3). On the contrary, bitumen always contains carbonaceous radicals $\mathrm{C}^{0}$, which originate from the degradation, diagenesis and catagenesis of fossil biological matter, so $k_{2}$ should be strictly positive. As the other biological compounds of embalming materials are much more recent than bitumen, they may or may not contain radicals, so that $k_{3} \geq 0$.

From Eqs.1, EPR intensity of radicals is related to that of VO-P by:

$$
I_{C^{0}}=\left(\frac{k_{2}-k_{3}}{k_{1}}\right) I_{V O-P}+k_{3}
$$

Except reference sample $\boldsymbol{T S}$, all the experimental data lie in the surface limited by the lines $I_{C^{0}} \approx 3 \times I_{V O-P}$ (full line) and $I_{C^{0}} \approx 5 \times I_{V O-P}$ (dashed line). Several pieces of information can be deduced from these results:

(i) These two lines intercept the origin, which corresponds to $k_{3} \approx 0$ and indicates that radicals $\mathrm{C}^{0}$ are almost exclusively localized in the bitumen component of the balm;

(ii) The fact that the ratios $k_{2} / k_{1}$ in historical and reference samples (except $\boldsymbol{T S}$ ) lie in a narrow range of values, 3 $\leq k_{2} / k_{1} \leq 5$, show that the bitumen originates from vanadium-rich sources, possibly the same, in all cases. This could indicate that the bitumen of historical samples originates from floating blocks the north part of the Dead Sea (vanadium rich) rather than from the south part (vanadium poor) $;^{10}$

(iii) The commercial bitumen of Judea ( $\boldsymbol{R e f} 2)$ is characterized by a higher ratio $k_{2} / k_{1} \approx 5$ than the Dead Sea asphalt $\boldsymbol{R e f} 1\left(k_{2} / k_{1} \approx 3\right)$, which can be due to a different geological setting for the source of $\boldsymbol{R} \boldsymbol{e f} \mathbf{2}$ (slightly depleted in VO-P) or to the chemical treatment used for obtaining the brown powder;

(iv) Again, the data points of Hum 3 and $\boldsymbol{R e f} \mathbf{2}$ are very close in the diagram.

Two hypotheses may be proposed to explain the similitude of these two data in two independent diagrams (Figs 5a and 5b): a) the bitumen of Ref 2 and Hum 3 come from the same geological setting, and b) the mummy Hum 3 has been partially restored with bitumen of Judea. Hypothesis b) is reinforced by the fact that Hum 3, unlike the other historical samples, contains no VO-nP complexes and is very rich in bitumen. This hypothesis is discussed in the last section of this article.

Out-of-phase EPR. X-band EPR spectra of historical samples (Figs.3b, S1 and S2) contain four types of overlapping spectra, i.e. free radicals $\mathrm{C}^{0}$, complexes VO-P and VO-nP, and traces of ferromagnetic particles. In the absence of simulation, such crowded spectra can be difficult to interpret. However, when paramagnetic species differ by their spin lattice relaxation times $T_{1}$, it is possible to improve the spectral selectivity by playing with the phase shift of the detected signal. In cw-EPR, the static magnetic field is harmonically modulated, generally at the frequency $\omega_{m} / 2 \pi=100 \mathrm{kHz}$ in standard spectrometers. The response of the spin system to the resulting modulation of the Zeeman interaction is phase shifted relative to the modulated field. ${ }^{28}$ Two components of the EPR signal can be detected: the in-phase and the out-of-phase components with respect to the static field modulation. The inphase detection is routinely used in standard EPR as it gives all the EPR signals present in the sample. The out of-phase signal is sensitive to phase retardation effects, so that it is sensitive only to EPR signals with long spin lattice relaxation times $T_{1}{ }^{29}$ EPR signals with short $T_{1}$ do not give out-of-phase signal. Figure 6 shows an example of EPR spectrum at X-band for Hum 1, recorded in-phase and out-of-phase with the modulation. The in-phase spectrum is the superposition of four different signals: the vanadyl complexes VO-P and VO-nP (marked by green circles), free radicals $\mathrm{C}^{0}$, and the broad line (iron oxide particles) distorting the baseline. The out-of-phase spectrum contains only the VO-P and $\mathrm{C}^{0}$ signals. This shows that these two species have longer $T_{1}$ than VO-nP complex. In-phase and out-of-phase spectra of other samples are given in Supporting Information (Fig. S4).

The amplitudes of the EPR lines of the out-of-phase signal (noted I') versus the in-phase signal (noted $I$ ) are shown in Fig.7a for $\mathrm{C}^{0}$ and in Fig.7b for the $-1 / 2 \perp$ transition of VO-P complexes. All the experimental points are roughly placed along lines with slopes 0.23 for radicals and 0.12 for VO-P, and they are nearly superimposed in the case of Hum 1 and Hum 2. Again, these diagrams show the relative proximity of Hum 3 and Ref 2 . As the out-of-phase signal is very sensitive to relaxation times $T_{1}{ }^{29}$ these almost linear relations between $I^{\prime}$ and $I$ for $\mathrm{C}^{0}$ and VO-P signals show that all the samples studied contain the same types of free radicals and VO-P complexes 
with the same chemical environment (which control $T_{1}$ ). Indeed, if some samples had contained species (radicals or complexes) with long $T_{1}$ and other species with short $T_{1}$, only those with long $T_{1}$ would give an out-of-phase signals. In such a situation, one would expect data scattered throughout the diagram.

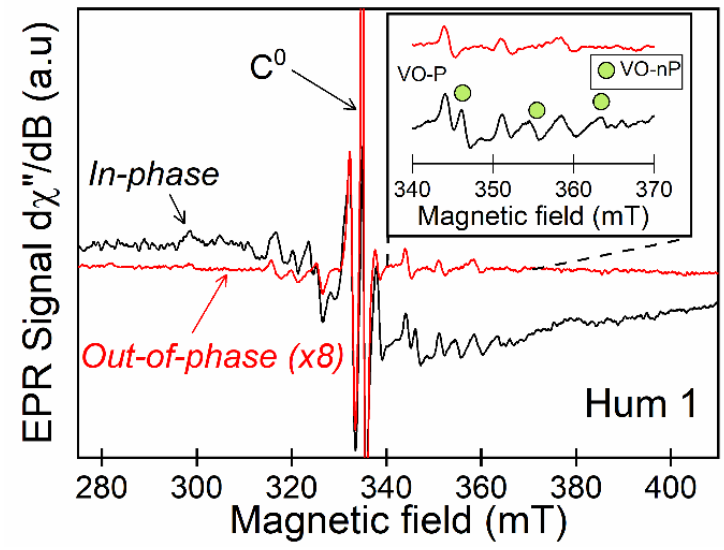

Figure 6. EPR spectra at room temperature of Hum 1 recorded in-phase (black) and out-of-phase (red) with respect to the modulation.

It is interesting to note that the out-of-phase behavior of the $\mathrm{C}^{0}$ line in bitumen $\boldsymbol{T S}$ (Clermont-Ferrand, France) is the same as that of $\mathrm{C}^{0}$ in all samples (Fig.7a). This shows that the $\mathrm{C}^{0}$ radicals have the same $T_{1}$ in all types of bitumen. For the sake of interpreting these results, let us consider the ratio $\rho=I$ '/I of the out-of-phase to in-phase signal amplitudes. Figure 7c represents the variation of $\rho$ for VO-P (noted $\rho_{\text {vo-P }}$ ) versus $\rho$ for $\mathrm{C}^{0}$ (noted $\rho_{\mathrm{C} 0}$ ) for all the samples. The data appear linearly correlated with $\rho_{\text {vo-P }} \approx$ $0.83 \rho_{\mathrm{C} 0}$, which is the indication of a simple relation between relaxation times of VO-P and $\mathrm{C}^{0}$ for all the samples.

The theory of out-of-phase EPR signals is rather complex ${ }^{29,30}$ however under reasonable assumptions, $\rho$ can be expressed as: ${ }^{31}$

$\rho \propto \omega_{m} T_{1} \frac{s}{1+s}$

where $s=\gamma_{e}^{2} B_{1}^{2} T_{1} T_{2}$ is the saturation factor, with $T_{1}$ and $T_{2}<T_{1}$ the spin-lattice and spin-spin relaxation times, respectively, $\gamma_{e}$ the electron gyromagnetic ratio, and $B_{1}$ the amplitude of the microwave field. Relaxation measurements in various asphaltene samples by Mamin et al. ${ }^{32}$ showed that relaxation times $T_{2}$ of radicals and VO-P are linked by the relation $T_{2}^{V O-P} \approx 0.43 \times T_{2}^{C^{0}}$. By fixing the experimental conditions, i.e $\omega_{m}$ and the microwave power $P \propto\left(B_{1}\right)^{2}$, and under low saturation condition ( $s$ $<1)$, which is the case with the present experiments, the ratio $\rho$ for $\mathrm{VO}-\mathrm{P}$ and $\mathrm{C}^{0}$ are linked by the following relationship deduced from expression (3):

$$
\begin{aligned}
\rho_{V O-P} & \approx\left(\frac{T_{1}^{V O-P}}{T_{1}^{C^{0}}}\right)^{2} \frac{T_{2}^{V O-P}}{T_{2}^{C^{0}}} \rho_{C^{0}} \\
& \approx 0.43\left(\frac{T_{1}^{V O-P}}{T_{1}^{C^{0}}}\right)^{2} \rho_{C^{0}}
\end{aligned}
$$

From the slope of the curve in Fig. 7c and from Eq.4, we can deduce that $T_{1}$ of VO-P and radicals are nearly equal $T_{1}^{V O-P} \approx 1.4 \times T_{1}^{C^{0}}$ in all samples. As $T_{1}$ depends not only on the nature of paramagnetic species, but also on their chemical environment, this nearly constant ratio between $T_{1}$ of VO-P and $\mathrm{C}^{0}$ indicates that their $T_{1}$ are correlated. It is known that VO-P and $\mathrm{C}^{0}$ are mainly located in the asphaltene component in oil and bitumen. ${ }^{17,32}$ Direct relaxation measurements by pulsed-EPR on a series of asphaltene samples showed that the distance between $\mathrm{C}^{0}$ and VO-P does not exceed a few nanometers, which results in a correlation between their $T_{1}{ }^{32}$ The closeness of $T_{1}$ in VO-P and $\mathrm{C}^{0}$ in all samples studied in this work indicated that this weak VO-P--- $\mathrm{C}^{0}$ interaction is conserved in black matter of all animal and human mummies and was not affected by the preparation of the embalming matter.

On the contrary, VO-nP complexes, which are found only in historical samples (except Hum 3), are systematically characterized by $\rho_{\mathrm{VO}-\mathrm{nP}}=0$ (Fig.7c), showing that their $T_{1}$ is very small, $T_{1}^{V O-n P}<<T_{1}^{V O-P}$ and $T_{1}^{V O-n P}<<T_{1}^{C^{0}}$. These inequalities suggest that the oxygenated VO-nP complexes originate from the extraction of $\mathrm{VO}^{2+}$ from VO-P complexes in an asphaltene environment, and their complexation by oxygenated ligands in a different environment.

\section{Paramagnetic markers of bitumen and authentication} of the black matter in Egyptian mummies.

VO-P complexes and carbonaceous radicals $\mathrm{C}^{0}$ are stable markers of oil and bitumen, ${ }^{10-12}$ and their detection by EPR in a black matter with complex composition is a direct and non-destructive method to reveal, without ambiguity, the presence of bitumen in its composition (Fig.4b). These markers are mainly localized in the asphaltene component of bitumen, which is the most resistant component to biodegradation and oxidation. ${ }^{13} \mathrm{C}^{0}$ and VO-P are spatially connected in asphaltene, which manifests by a correlation between their relaxation times. ${ }^{32}$ By using combination of in-phase and out-of-phase detection, we observed such a correlation between relaxation times, which demonstrate that the nanostructuration of VO-P and $\mathrm{C}^{0}$, is conserved in bitumen of historical samples (Fig.7). This result strongly suggests that bitumen was not chemically and/or biologically modified during the preparation of the embalming matter and after burial of the mummy. 


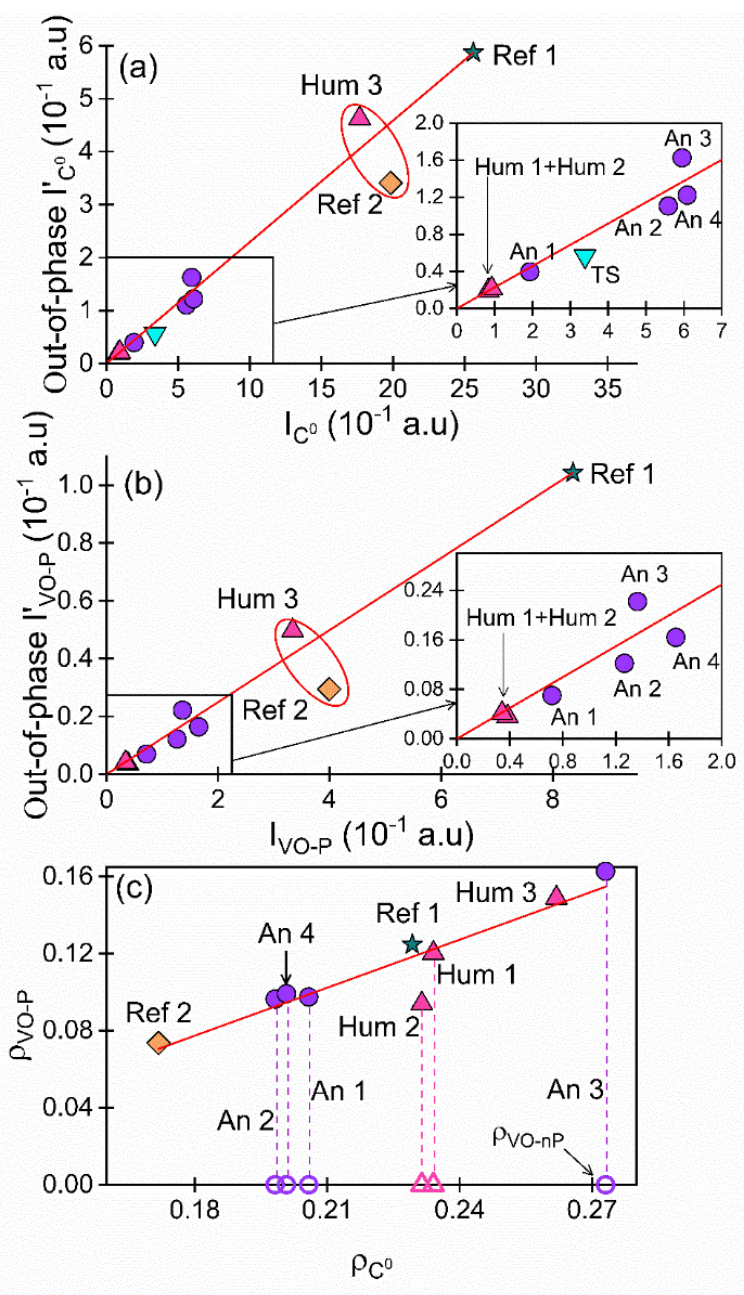

Figure 7. Out-of-phase versus in-phase EPR amplitude for a) radicals $\mathrm{C}^{0}$; b) VO-P complex; c) diagram showing the correlation between the ratio $\rho=I^{\prime} / I$ of VO-P and $\mathrm{C}^{0}$.

Historical samples (except Hum 3) contains also nonporphyrinic VO-nP complexes, where $\mathrm{VO}^{2+}$ ions have four oxygen ligands. Contrary to VO-P, these VO-nP are not associated with carbonaceous radicals $\mathrm{C}^{0}$ of the bitumen (their relaxation times $T_{1}$ are not correlated). Three possible origins can be proposed for the presence, in the embalming black matter, of such oxygenated vanadyl complexes: (i) First, VO-nP could originate from weathering alteration at ambient temperature over thousands of years after burial; (ii) second, they could be the result of biodegradation by bacteria, insects or fungi present in the mummy; (iii) third, VO-nP could originate from reaction of VO-P with carboxylate functions of other biological compounds of the balm mixture. At first sight, mechanisms (i) is probably not predominant as such VO-nP complexes have not been observed in extensively weathered tar ball coming from the 2010 Deepwater Horizon oil spill in the Gulf of Mexico, ${ }^{33}$ which indicates that even an intense weathering is not sufficient to produce VO-nP complexes. Indeed, VO-P complexes are known to be very stable, and temperatures larger than $400^{\circ} \mathrm{C}$ are required for their destruction. ${ }^{10}$ The formation of VO-nPtype complexes in asphaltene is possible only by heating several days at $250^{\circ} \mathrm{C}$ in air. ${ }^{34}$ Mechanisms (ii) and (iii) appear more reasonable. Mummies generally present evidence of alteration by microorganisms, insects and fungi. ${ }^{35,36}$ Also it is known that microbial growth and biodegradation of oil spills is stimulated by trace metal elements. ${ }^{37,38}$ As bitumen contains $\mathrm{Ni}$ and VO porphyrins, these complexes may be somewhat modified by the microbial activity. For example, peroxidase enzymes are known to produce a demetallation of petroporphyrins, ${ }^{39}$ i.e an extraction of $\mathrm{VO}^{2+}$ ions from VO-P, which may hereafter stabilize by forming oxygenated VO-nP complexes. Regarding mechanism (iii) we may also propose that $\mathrm{VO}^{2+}$ ions of VO-P located at the interface between bitumen and other biological components of the black matter (plant oil, tree resin, beeswax, animal fats...) form VO...O bonds by complexation with carboxylate functions present in these agents (a schematic model is presented in Fig.8). A combination of mechanisms (ii) and (iii) could also be considered, in which microbial activity could result in the extraction of $\mathrm{VO}^{2+}$ ions from VO-P complexes, followed by their complexation by the oxygenated functions of other biomolecules of the black matter.

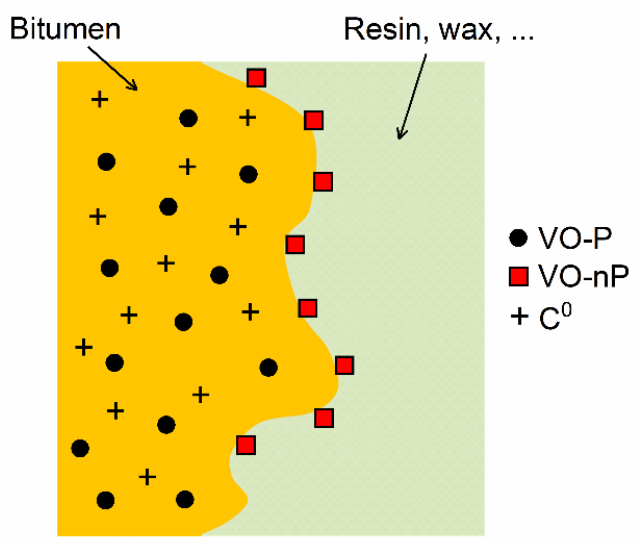

Figure 8. Schematic model showing the non-porphyrinic vanadyl complexes VO-nP at the interface between bitumen and the vegetal component of the embalming material.

Let us now consider the case of sample Hum 3, which was taken from the mummy found in Nehemsimontou's coffin (XXV th dynasty, 744 BC to 656 BC). The ensemble was purchased in 1837 from a private collector by the municipality of Boulogne, France. But it later turned out that the mummy and the coffin had nothing in common, and that they had been assembled for the purpose of a better sale, a common practice in the $19^{\text {th }}$ century. It is the mummy of a bearded man with short, curly hair, about $1.69 \mathrm{~m}$ tall (Fig. 1c). The body is coated with a solid, black, shiny substance, which drips in some places. ${ }^{40}$ Hum 3 was sampled from the neck of the mummy, and has many EPR characteristics that make it different from 
the other historical samples investigated in this work: (i) a high abundance of VO-P, suggesting that it is pure (or almost pure) bitumen (Fig.4b), as also demonstrated by GC/MS analysis (Supporting Information); (ii) the absence of VO-nP, an evolution marker found in all other historical samples (Fig. 5a); (iii) a $\mathrm{C}^{0} / \mathrm{VO}-\mathrm{P}$ intensity ratio different from other historical samples and similar to that of a reference sample, the commercial bitumen of Judea Ref 2 (Fig.5b). All these features suggest that the mummy was covered with bitumen, which has not been altered by subsequent chemical or biological reactions. As also supported by molecular data, we must thus consider the possibility that this mummy was restored with pure bitumen before it was acquired by the museum of Boulogne in 1837.

\section{CONCLUSION AND PERSPECTIVE}

EPR of vanadyl complexes and carbonaceous radicals of asphaltene is a non-destructive tool to study embalming material in ancient Egypt. As VO-P complexes are ubiquitous in petroleums, asphalts and bituminous rocks of marine origin in all continents and in geological formations with a wide range of age, their detection in archaeological balms unambiguously indicates the presence of bitumen in this material. Also, carbonaceous radicals are present in all kerogeneous materials, and originate from the maturation of biomolecules during tens to hundreds of million years of geological evolution. They are also present in asphaltene of all bitumen, whether of marine origin or not. These radicals are absent in more recent biological materials, so that the presence of both VO$\mathrm{P}$ and radicals in the complex mixture of embalming materials is a very sensitive marker of presence of a bitumen component in this black material. An advantage of standard cw-EPR at X-band is the fact that millimeter-size sample can be studied without any chemical preparation. As bitumen content in balms is generally underestimated by the molecular analysis approach currently used in most archaeometric studies, ${ }^{41}$ EPR is a rapid and sensitive complementary method to detect bitumen. Even in the case of complex EPR spectra containing overlapping signals of different nature, VO-P and carbonaceous radicals can be selectively detected by using out-of-phase detection mode of the EPR signal. This approach is new for the best of our knowledge.

Other conclusions of this work are summarized as follow: (i) VO-P and $\mathrm{C}^{0}$ markers of bitumen are well protected against biodegradation and atmospheric degradation in the highly polymerized asphaltene component of bitumen; (ii) The conservation, in historical samples, of the nanostructuration of VO-P and $\mathrm{C}^{0}$ radicals in the bitumen component of balms (revealed by the correlation between their relaxation times $T_{1}$ ) indicates that the natural bitumen (most probably taken from the Dead Sea) was not affected by the mixture with other embalming agents; (iii) The black matter sampled from mummies and coffin also contains non-porphyrinic vanadyl VO-nP complexes with oxygenated ligands replacing the nitrogen ligands of porphyrin ring. They probably originate from the biological and/or chemical reaction of VO-P with carboxylate functions of the vegetal or animal components of the balm; (iv) one sample taken from a human mummy does not contain this VO-nP marker, and is made of pure unaltered bitumen. This suggests that this mummy could have been partially restored in the early $19^{\text {th }}$ century.

Although more quantitative analyses of these markers are needed for eventual dating and authentication applications, the absence of VO-nP could be used to detect any undocumented restoration of mummies with bitumen. This may be useful for the analysis of objects containing dark matter, once acquired by museums through donations or purchases from private collectors in the 19th century, at a time when many excavations of archaeological sites often resembled pillaging. Also, although most of the bitumen used in mummies or their wooden coffins came from Dead Sea area in Palestine, ${ }^{1,21,42-44}$ it is necessary to compare historical bitumen with bitumen from other sources, for example Gebel El Zeit, Gulf of Suez, that have sometimes been used by ancient Egyptian. ${ }^{20,45}$

For future research, a detailed analysis of the structure and surrounding of vanadyl complexes (porphyrinic and non-porphyrinic) and radicals by more sophisticated EPR techniques would provide clues to the fabrication receipts and the evolution/degradation of embalming materials. First, Electron Nuclear Double Resonance (ENDOR) spectroscopy will provide additional information on the evolution of VO-P complexes, by probing hyperfine interactions with ${ }^{1} \mathrm{H}$ nuclei of metallic complexes and radicals. $^{46}$ Second, pulse-EPR methods will allow direct measurements of relaxation times $T_{1}$ and $T_{2}$, and measurement of small hyperfine interactions with ${ }^{14} \mathrm{~N},{ }^{13} \mathrm{C},{ }^{31} \mathrm{P}$ and ${ }^{33} \mathrm{~S}$ nuclei. ${ }^{17,32,47}$ However, the ease of use of standard continuous wave X-band EPR spectroscopy (recording a spectrum takes only a few minutes) and the ubiquity of vanadyl geoporphyrins VO-P and radicals in bitumen, open the door to the easy characterization of bitumen in all types of archaeological artefacts. Our novel approach can be complementary to another recent relevant study. ${ }^{48}$

\section{ASSOCIATED CONTENT}

\section{Supporting Information}

The Supporting Information is available free of charge on the ACS Publications website.

Description of samples; EPR spectra of references and historical samples; EPR spectrum of $T S$ sample; In-phase and out-of-phase EPR spectra; Simulation parameters; Sample preparation and GC/MS analyses.

\section{AUTHOR INFORMATION}

\section{Corresponding Author}

*E-mail: didier.gourier@chimieparistech.psl.eu;OORCID Didier Gourier : 0000-0002-9996-9297 


\section{*E-mail: Charles.dutoit@ chimieparistech.psl.eu}

\section{Author Contributions}

CED, LB and DG performed and interpreted EPR measurements, $\mathrm{HF}$ and AL analyzed the samples by GC/MS. The manuscript was written by DG through contributions of all authors. All authors have given approval to the final version of the manuscript.

\section{ACKNOWLEDGMENT}

We thank Aurélie Artizzu for providing information about some historical samples studied in this work. The authors are very grateful to the Musée Dobrée in Nantes, the Musée d'Art et d'Histoire in Narbonne, the Musée des Confluences in Lyon and the Chateau-Musée de Boulogne-sur-Mer and more especially to Julie Pellegrin, Camille Broucke, Flore Collette, Elikya Kandot and Gaëlle Etesse who are in charge of collections. In addition, we would like to express our gratitude to Noëlle Timbart, curator at the C2RMF for her fruitful help, to Nathalie Balcar, conservation scientist at the C2RMF for the mummy samples and informative exchanges, and to Armelle Charrié for analytical data.

\section{REFERENCES}

(1) Maurer, J.; Möhring, T.; Rullkötter, J.; Nissenbaum, A. J. Arch. Sci. 2002, 29, 751-762.

(2) Buckley, S.A.; Clark, K.A.; Evershed, R.P. Nature 2004, 43, 294-298.

(3) Clark, K.A.; Ikram, S.; Evershed, R.P. Phil. Trans. R. Soc. A 2016, 374, 20160229.

(4) Granville, A.B. Phil. Trans. R. Soc. 1825, 4115, 269-316

(5) Lucas, A. J. Egypt. Archaeol. 1914, 1, 241-245.

(6) Spielmann, P.E. J. Egypt. Archaeol. 1933, 18, 177-180.

(7) Lucas, A.; Harris, J.R. in Ancient Egyptian Materials and Industries, Histories and Mysteries of Man, Ltd London, IV ${ }^{\text {th }}$ Ed. 1989, 523 p.

(8) Buckley, S.A.; Evershed, R. Nature 2001, 413, 837-841.

(9) Breit, G.N.; Wanty, R.B. Chem. Geol. 1991, 91, 83-97.

(10) Premovic, P.I.; Tonsa, I.R.; Pavlovic, M.S.; Lopez, L.; LoMonaco, S. Fuel 1998, 77, 1769-1776.

(11) Rullkötter, J.; Spiro, B.; Nissenbaum, A. Geochim. Cosmochim. Acta 1985, 49, 1357-1370

(12) Baker, E.W.; Louda, J.W. In Biological Markers in the Sedimentary Record; John, R.B. Ed.; Elsevier: Amsterdam, Netherlands, 1986, pp 125-225.

(13) Connan, J.; Zumberge, J.; Imbus, K.; Moghaddam, A. Organic. Geochem. 2008, 39, 1772-1789.

(14) Stoll, S.; Schweiger, A. J. Magn. Reson. 2006, 178, 42-55.

(15) Saraceno, A.J.; Coggeshall, N.D.; Fanale, D.T. Anal. Chem. 1961, 33, 500-505.

(16) Aizenshtat, Z.; Sundararaman, P. Geochim. Cosmochim. Acta 1989, 53, 3185-3188.

(17) Ben Tayeb, K; Delpoux, O.; Barbier, J.; Marques, J. ; Verstraete, J. ; Vezin, H. Energy \& Fuels 2015, 29, 4608-4615.

(18) Goodman, B.A.; Raynor, J.B. In Electron spin resonance of transition metal complexes, Advances in Inorganic Chemistry and Radiochemistry; Emeleus, H.J.; Sharpe, A.G. Eds.; Academic Press: New York, 1970.

(19) Gourier, D.; Delpoux, O.; Bonduelle, A.; Binet, L.; Ciofini, I. ; Vezin, H. J. Phys. Chem. 2010, 114, 3714-3725.

(20) Harrell, J.A.; Lewan, M.D. Archaeometry 2002, 44, 285-293.

(21) Nissenbaum, A.; Buckley, S. Archaeometry 2013, 55, 563568.

(22) Connan, J.; Van de Velde, T. Arab.Arch.Epig. 2010, 21, 1-19.

(23) Nissenbaum, A.; Rev. Chem. Engin. 1994, 9, 365-383.
(24) Skrypczak-Bonduelle, A. ; Binet, L.; Delpoux, O. ; Vezin, H. ; Derenne, S. ; Robert, F. ; Gourier, D. Appl. Magn. Reson. 2008, 33, 371-397.

(25) Bourbin, M. ; Gourier, D.; Derenne, S.; Binet, L.; Le Du, Y. ; Westall, F. ; Kremer, B. ; Gautret, P. Astrobiology 2013, 13, 151-162.

(26) Binet, L.; Gourier, D. ; Derenne, S. ; Robert, F. Geochim. Cosmochim. Acta 2002, 66, 4177-4186.

(27) Gourier, D.; Binet, L.; Calligaro, T.; Capelli, S.; Vezin, H.; Bréhéret, J. ; Hickman-Lewis, K.; Gautret, P. ; Campbell, K. ; Westall, F. Geochim. Cosmochim. Acta 2019, 258, 207-225.

(28) Abragam. A. In The Principles of Nuclear Magnetism, Marshall, W.C.; Wilkinson, D.H. Eds. Oxford Univ. Press, Oxford 1961.

(29) Livshits, V.A.; Pali, T.; Marsh, D. J. Magn. Reson. 1998, 134, 113-123.

(30) Kalin, M.; Gromov, I.; Schweiger, A. J. Magn. Reson. 2003, 160, 166-182.

(31) Livshits, V.A.; Marsh, D. J. Magn. Reson. 2005, 175, $317-$ 329.

(32) Mamin, G.V.; Gafurov, M.R; Yusupov, R.V.; Gracheva, I.N.; Ganeeva, Yu.M.; Yusupova, T.N.; Orlinskii, S.B. Energy Fuels 2016, 30, 6942-6946.

(33) Ramachandran, V.; van Tol, J.; McKenna, A.M.; Rodgers, R.P.; Marshall, A.G.; Dalal, N.S. Anal. Chem. 2015, 87, 2306-2313.

(34) Premovic, P.I.; Tonsa, I.R.; Pajovic, M.T.; Lopez, L.; Monaco, S.L.; Dordevic, D.M.; Pavlovic, M.S. Fuel 2001, 80, 635639.

(35) Gülaçar, F.O.; Susini, A.; Klohn, M. J. Archaeol. Science 1990, 17, 691-705.

(36) Arya, A.; Shah, A.R.; Sadasivan, S. Current Science 2001, 7 793-799.

(37) Rio Medeles, G.; Abe, A.; Saito, K.; Asano, K.; Saito, K.; Yokota, A.; Tomita, F. J. Bioscience and Bioengineering 2000, 90, 515-521.

(38) Mejeha, O.K.; Head, I.M.; Sherry, A.; McCann, C.M.; Leary, P.; Jones, D.M.; Gray, N.D. Chemosphere 2019, 237, 124545.

(39) Fedorak, P.M.; Semple, K.M.; Vazquez-Duhalt, R.; Westlake, D.W.S. Enzyme Microb. Technol. 1993, 15, 429-437.

(40) Vincent, F. C2RMF report $n^{\circ} 6307,2004$.

(41) Lucejko, J.; Connan, J.; Orsini, S. ; Ribechini, E. ; Modugno, F. J. Archaeol. Science 2017, 85, 1-12.

(42) Rullkötter, J.; Nissenbaum, A. Naturwissenschaften 1988, 75, 618-621.

(43) Connan, J.; Dessort, D. C.R.Acad.Sci. Paris série II. 1991, $312,1445-1452$.

(44) Connan, J.; Nissenbaum, A.; Dessort, D. Geochim. Cosmochim. Acta. 1992, 56, 2743-2759.

(45) Barakat, A.O.; Mostafa, A.; Qian, Y.; Kim, M.; Kennikut II, M.C. Geoarcheology: An International Journal 2005, 20, 211-228.

(46) Mannikko, D.; Stoll, S. Energy Fuels 2019, 33, 4237-4243.

(47) Biktagirov, T.; Gafurov, M.; Mamin, G.; Gracheva, I.; Galukhin, A.; Orlinskii, S. Energy Fuels 2017, 31, 1243-1249.

(48) Fulcher, K.; Stacey, R.; Spencer, N. Nature Sci. Rep. 2020, 10,8309 . 
Table of Contents
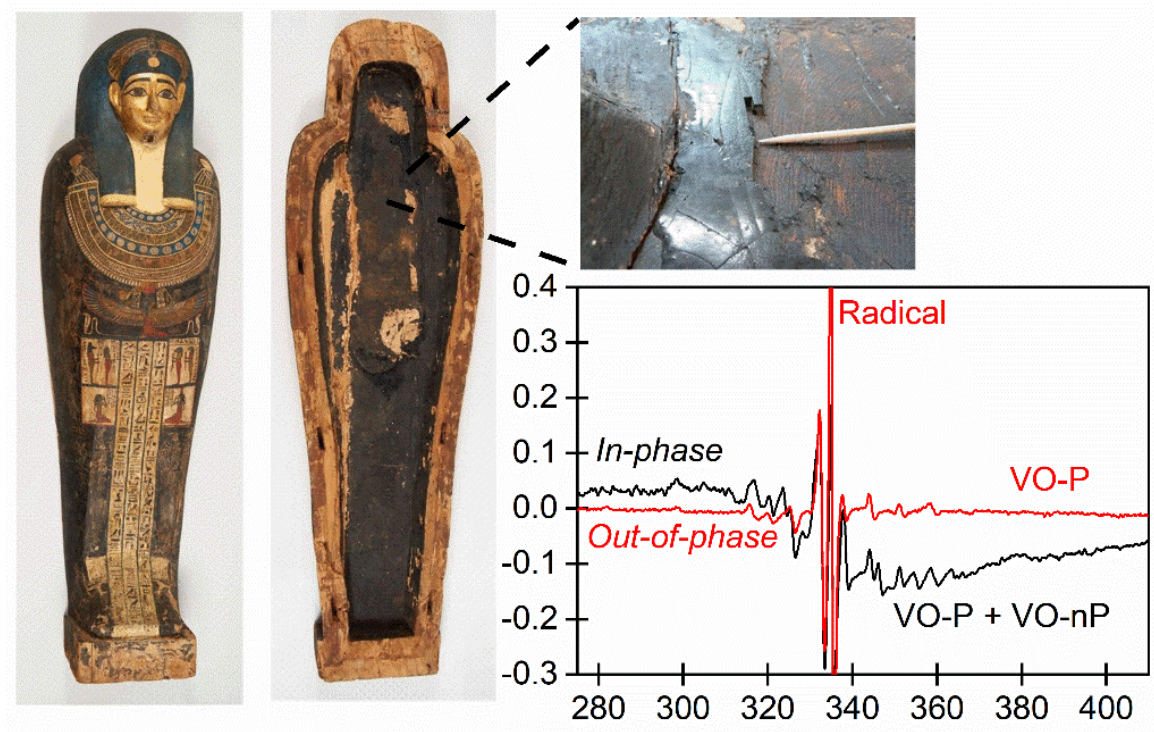